\title{
Caso clínico radiológico
}

\author{
JULIO MAGGIOLO M. ${ }^{1}$, LILIAN RUBILAR O. ${ }^{1}$, RICARDO KOGAN A. ${ }^{1}$
}

1. Médico, Unidad Broncopulmonar. Hospital Exequiel González Cortés.

\section{Historia clínica}

Paciente de sexo masculino, producto de embarazo normal, parto normal. Peso de nacimiento: $3620 \mathrm{~g}$, talla $50 \mathrm{~cm}$, período de recién nacido inmediato normal, padres sanos.

A la edad de 28 días de vida, comenzó con secreción ocular bilateral, coriza mucosa. Aproximadamente 5 días más tarde, se agregó tos que progresivamente se hace paroxística, emetizante, asociada a cianosis peribucal, sin apnea $\mathrm{y}$ sin fiebre.

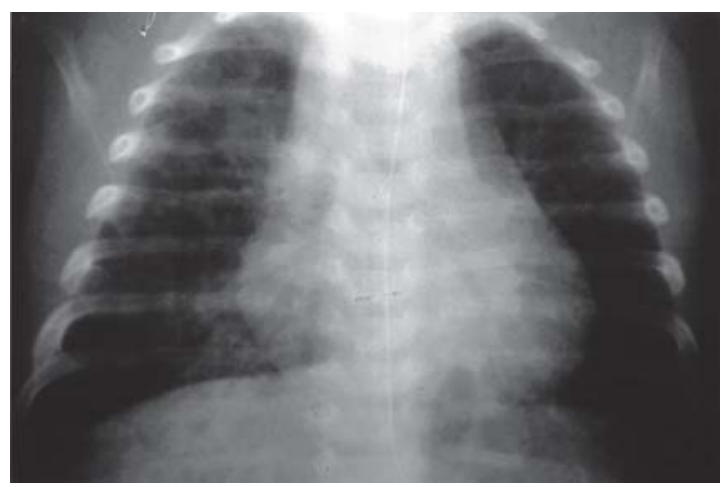

Figura 1a.
A la edad de 1 mes 7 días consultó en el servicio de urgencia del Hospital Exequiel González Cortés en regulares condiciones generales, tos en accesos, cianosis peribucal, retracción de partes blandas, secreción ocular purulenta bilateral, afebril, frecuencia respiratoria de 65/min, frecuencia cardíaca de 163/ min, saturometría de 95\%. A la auscultación pulmonar: murmullo vesicular disminuido difusamente, crépitos en ambas bases, estertores medios y sibilancias escasas. Se solicitó radiografía (Rx) de tórax (figura 1).

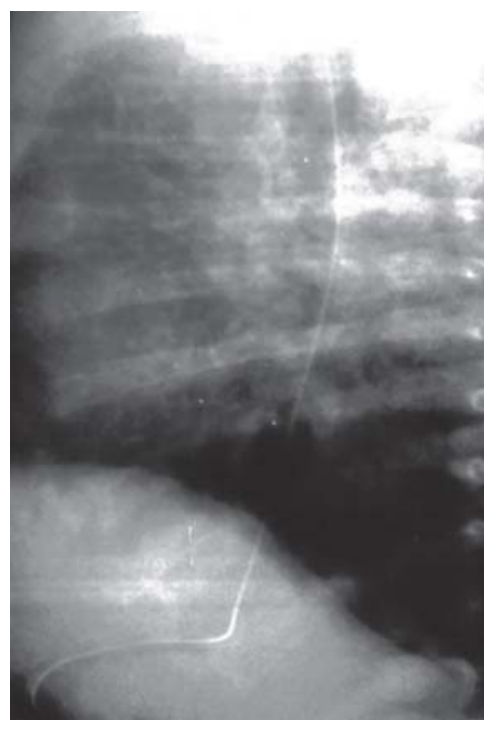

Figura $1 b$.

\section{¿Cuál es su diagnóstico?}

Trabajo recibido el 25 de octubre de 2007, devuelto para corregir el 22 de noviembre de 2007, segunda versión el 30 de noviembre de 2007, aceptado para publicación el 15 de enero de 2008. 


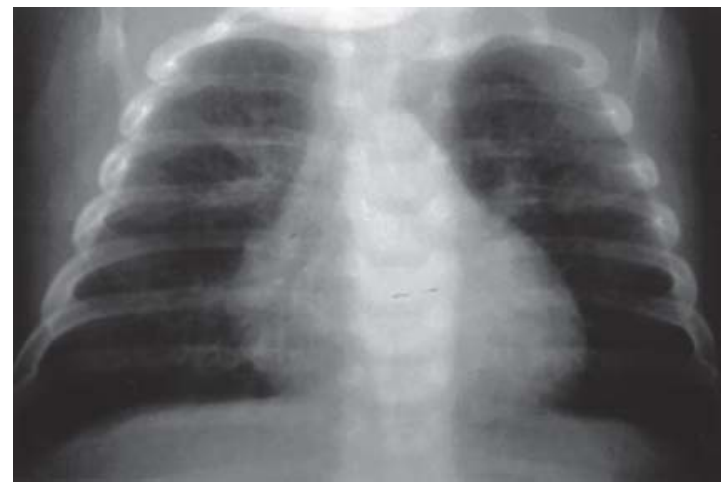

Figura 2a.

\section{Hallazgos radiológicos}

La figura 1 muestra sombras de predominio intersticial, reticulonodulares en ambos pulmones, en especial en las regiones centrales. Hay también algunas áreas de compromiso alveolar en ambos lóbulos inferiores, donde se observan también zonas de atelectasia.

\section{Evolución clínica}

Durante la hospitalización, el paciente presentó dificultad respiratoria moderada, polipnea, retracción de partes blandas, tos paroxística, con requerimiento de 1 lt/min de oxígeno. Evolucionó con episodios de mayor obstrucción bronquial que requieren ser tratados con Salbutamol 2 puff cada 10 minutos por 5 veces, en varias oportunidades. Además se agregó betametasona (endovenoso) por 3 días y posteriormente prednisona por 7 días.

Se solicitó hemograma que muestra una leucocitosis de 25100 cels/ $\mathrm{mm}^{3}$, eosinofilia de 753 cels $/ \mathrm{mm}^{3}$, proteína C reactiva normal, inmunofluorescencia indirecta viral negativa, inmunofluorescencia directa para Bordetella pertussis negativa.

Por tratarse de un lactante menor de 3 meses de edad, presencia de tos paroxística, conjuntivitis purulenta bilateral, ausencia de fiebre, eosinofilia, Rx tórax que reveló imágenes de predominio intersticial intersticiales micronodulares difusas, bilaterales, se planteó una neumonía por Chlamydia trachomatis, se soli-

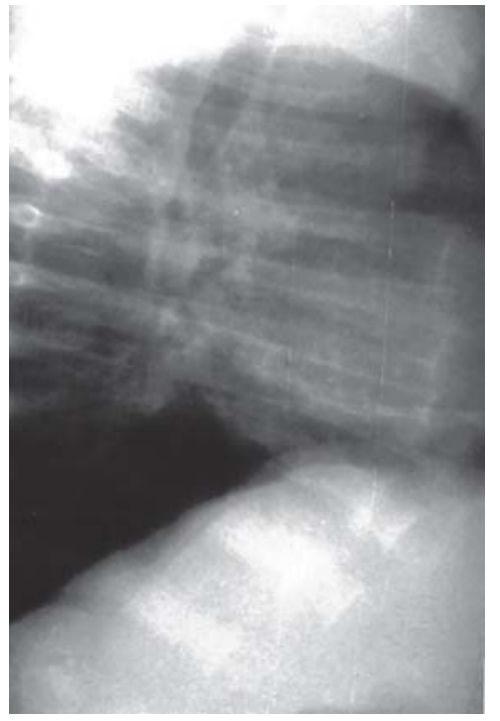

Figura 2 b.

citó microinmunofluorescancia indirecta (MIFI) para este agente, la que resultó positiva, por lo que se decidió administrar claritromicina durante 14 días.

El paciente mostró una reducción importante de los síntomas, con disminución de la tos, siempre tormentosa, pero no paroxística, sin cianosis, mejoró la conjuntivitis, disminuyeron las crepitaciones y los episodios de obstrucción bronquial, el aporte de oxígeno se suspendió al octavo día de hospitalización.

Luego de permanecer hospitalizado durante 11 días, se dió de alta en buenas condiciones, sin dificultad respiratoria, con escasa tos.

Fue controlado en la unidad de broncopulmonar un mes después de iniciado el cuadro clínico y sin síntomas respiratorios. En ese momento una Rx de tórax (figura 2) mostró reducción significativa de las sombras pulmonares bilaterales.

\section{Diagnóstico}

Neumonía del primer trimestre por Chlamydia trachomatis.

\section{Discusión}

Chlamydia trachomatis es una bacteria 
gram negativa, intracelular obligada, se replica por fisión binaria, posee pared celular, ADN y ARN, carece de péptidoglucano, que sólo forma transitoriamente. Posee un ciclo de desarrollo bifásico en el que se alternan el corpúsculo elemental, forma extracelular infectiva y el cuerpo reticulado, intracelular replicativo.

En los lactantes se infectan las células del epitelio cilíndrico del tracto respiratorio con respuesta de polimorfonucleares, predominando los eosinófilos y neutrófilos. Se sugiere que la patogenia es parcialmente autoinmune a través de antígenos sensibilizantes.

La transmisión ocurre principalmente a través del canal del parto en madres con infección cervico-uterina, sin embargo, hay casos aislados descritos en parto por cesárea (con rotura prematura ovular) o en período postnatal por la madre o por el personal de atención infectados (contagio mano-ojo).

El $30-50 \%$ de los pacientes presenta conjuntivitis, sólo 12-20\% tiene neumonía y en 20\% se acompaña de rinitis. Inicialmente el niño es inoculado en los ojos, nasofaringe o ambas y secundariamente puede ocurrir la infección del pulmón.

Éste microorganismo compromete el aparato urogenital del hombre y la mujer, se le asocia a parto prematuro, bajo peso al nacer, muerte fetal e infección ovular.

En Chile, la portación de este agente es de $4,7 \%$ en mujeres sexualmente activas bajo control ginecológico habitual. La infección por Chlamydia trachomatis es más común en familias con malas condiciones sociales y económicas, en aquellas con gran promiscuidad sexual $\mathrm{y}$ en mujeres solteras menores de edad, con cambio frecuente de pareja.

Estudios nacionales muestran una baja prevalencia de neumonía por Chlamydia. León y cols. En un estudio de infecciones agudas respiratorias bajas en lactantes hospitalizados encontraron este agente en un 10,4\% de los lactantes menores de 6 meses. En otro estudio, Kogan y cols. En un estudio de pacientes ambulatorios y hospitalizados, encontraron Chlamydia trachomatis en un $2 \%$ de los pacientes.

Las principales características clínicas de la neumonía por Chlamydia trachomatis consisten en inicio de la enfermedad entre las 4-16 semanas de vida, comienzo gradual, con obstrucción nasal, taquipnea moderada, tos generalmente paroxística, que interfiere con el sueño $\mathrm{y}$ en ocasiones emetizante. El curso es afebril, con compromiso conjuntival en la mitad de los casos. La auscultación puede revelar crepitaciones o estertores medianos, ausencia de sibilancias. La evolución es en general benigna, sin embargo, en lactantes menores desnutridos, prematuros o recién nacidos de bajo peso puede ser grave, con apnea, insuficiencia respiratoria, requerimiento de apoyo ventilatorio o desenlace fatal. El cuadro clínico en algunos casos no difiere del originado por otros patógenos, como Citomegalovirus, Bordetella pertusis, virus sincicial respiratorio, entre otros.

La Rx tórax muestra imágenes intersticiales, retículonodulares en ambos pulmones, en especial en las regiones centrales y puede haber hiperinsuflación pulmonar. Característicamente estas sombras presentan una evolución subaguda y tienden a persistir en el tiempo. Algunas neumonía virales pueden presentar un patrón radiológico similar, en especial la infección por Citomegalovirus.

Desde el punto de vista del laboratorio destaca hemograma con eosinofilia, VHS y PCR normales y aumento de las inmunoglobulinas séricas. El diagnóstico de Chlamydia trachomatis en conjuntivitis neonatal puede ser efectuado por técnicas inmunológicas, con una sensibilidad de 90 a 95\%, en cambio la sensibilidad en muestras nasofaríngeas varía entre 33 a 99\% respecto al cultivo celular, por otra parte las técnicas moleculares (reacción en cadena de polimerasa) han sido escasamente evaluadas en la neumonía neonatal.

Estudios iniciales muestran que los lactantes con neumonía desarrollan títulos de IgM específicas de $>1$ : 32 mediante MIFI, con buena especificidad respecto al cultivo celular, sin embargo, se desconoce la sensibilidad de la serología y faltan estudios que la comparen con técnicas moleculares para el diagnóstico de esta bacteria.

La histopatología pulmonar muestra neumonitis intersticial, con predominio de eosinófilos y células plasmáticas.

El tratamiento de la neumonía es con macrólidos: eritromicina $50 \mathrm{mg} / \mathrm{kg} /$ día cada 6 
hrs. Por 14 días, claritromicina 15 mg/kg/día cada 12 hrs. Por 14 días o azitromicina $10 \mathrm{mg} /$ $\mathrm{kg} /$ día por una vez por 3 días o $10 \mathrm{mg} / \mathrm{kg} /$ día por una vez por 1 días o $5 \mathrm{mg} / \mathrm{kg} /$ día por una vez por 4 días.

El control prenatal, el tratamiento de las mujeres infectadas y sus parejas constituyen medidas eficaces para evitar la transmisión a los hijos. La educación sexual especialmente dirigida a las familias con factores de riesgo es necesaria para disminuir la incidencia de esta patología.

En nuestro paciente, los síntomas clínicos corresponden a una neumonía por Chlamydia de evolución grave, con insuficiencia respiratoria, requerimiento de oxígeno por 8 días y gran componente obstructivo, hecho no habitual en el lactante menor con peso de nacimiento normal y parto de término. Es posible la asociación con algún agente viral, sin embargo, el estudio fue negativo para aquellos que se analizaron (virus respiratorio sincicial, adenovirus, parainfluenza e influenza). La respuesta clínica y radiológica a la terapia con claritromicina fue rápida.

Es posible que la baja incidencia de Chlamydia trachomatis como responsable de neumonía en pacientes hospitalizados, sea diferente a aquellos vistos en el policlínico de atención primaria, lugar donde probablemente el número de consultas por neumonía por Chlamydia sea mayor y de evolución benigna, beneficiada con el uso de terapia precoz con macrólidos ante la presentación de la enfermedad como síndrome coqueluchoídeo. Sería interesante conocer la incidencia en la atención primaria, lo que daría una mejor información de la enfermedad pulmonar por Chlamydia trachomatis.

\section{Referencias}

1.- Schochter J, Grossman M, Azimi PH: Serology of chlamydia trachomatis in infants. J Infect Dis 1982; 146: 530-5.

2.- Wang SP, Grayston JT: Microimmunoflurescence antibody responses in chlamydia trachomatis infection: a review. In: Marich PA, Holmes KK, Oriel JD. Eds. Chlamydial infections. Amsterdam: Elsevier Biomediacal Press 1982; 301-16.

3.- Tipple MA, Beem MO, Saxon EM: Clinical characteristics of the afebrile pneumonia associated with chlamydia trachomatis infection in infants less then 6 months of age. Pediatrics 1979; 63: 192-7.

4.- Stagno S, Bransfield DM, Brown MB, et al: Infant pneumonitis associated citomegalovirus, chlamydia, pneumocystis and ureaplasma: a prospective study. Pediatrics 1981; 68: 322-9.

5.- León A, Ceruti E, Díaz A, Pinto R, et al: Etiología de las infecciones respiratorias agudas bajas en lactantes hospitalizados. $3^{\mathrm{a}}$ parte: investigación de chlamydia trachomatis. Rev Chil Pediatr 1990; 61: 242-7.

6.- Rettig P: Infections due to chlamydia trachomatis from infancy to adolescence. Pediatr infect dis 1986; 4: 449-57.

7.- Best D, Ford CA, Miller WC: Prevalence of chlamydia trachomatis and neisseria gonorrhoeae infection in pediatric practice. Pediatrics 2001; 108: 103-9.

8.- Salas R, Pinto M: Chlamydia trachomatis en recién nacidos de un servicio de neonatología: cuatro casos. Rev Chil Pediatr 2000; 71: 423-6.

9.- Martínez MA, Diomedi A, Kogan R, et al: Taxonomía e importancia clínica de las nuevas familias del orden chlamydiales. Rev Chil Infect 2001; 18: 203-11.

10.- Martínez MA, Kogan R, Rojas P, et al. Diagnosis of chlamydia in community acquired pneumonia in children in chile. Act Paediatr 2000; 89: 650-3.

11.- Kogan R, Martínez MA, Rubilar L, et al: Comparative randomized trial of azithromycin versus erythromycin and amoxicillin for treatment of community acquired pneumonia in children. Pediatr Pulmonol 2003; 35: 91-8.

12.- Hammerschlag M: Chlamydia and chlamydiales: beyond chlamydia trachomatis. Pediatr Infect Dis 2007; 26: 639-40. 